\title{
PESQUISA DE Listeria monocytogenes EM SORVETES EXPRESSO E DE BUFFET COMERCIALIZADOS NA CIDADE DE JOAÇABA, SANTA CATARINA - BRASIL
}

\author{
Roberto Degenhardt \\ degenhardt_sc@yahoo.com.br \\ Fernanda Cavali da Silva \\ fer_biologia@yahoo.com.br
}

\begin{abstract}
RESUMO: Listeria monocytogenes é o patógeno causador da listeriose, e encontra nos neonatos, mulheres grávidas, idosos e pessoas imunodeprimidas seu grupo de risco. Essa bactéria pode estar presente nos alimentos, mesmo os em estado de refrigeração, onde pode sobreviver e se multiplicar. $O$ sorvete é um alimento obtido através de uma mistura de leite e outros ingredientes, que podem sofrem contaminações de ordem microbiológica. Diante dessa possibilidade, este estudo foi realizado para verificar a contaminação por Listeria monocytogenes em sorvetes comercializados em sete estabelecimentos no município de Joaçaba, SC. Foram coletadas 32 amostras de sorvetes, 16 servidas em buffet e 16 do tipo expresso, nos meses de janeiro e fevereiro de 2009. Foi observado um índice de contaminação por bactérias do gênero Listeria de $25,44 \%$, sendo $9,8 \%$ L. monocytogenes, $6,25 \%$ L. ivanovii, 3,13\% L. welshimeri. L. innocua foi detectada simultaneamente com L. grayi em uma amostra (3,13\%), e L. grayi ocorreu isoladamente em uma outra amostra (3,13\%). Os dados demonstraram um alto índice de presença do gênero Listeria, sobretudo nos sorvetes servidos em buffet, merecendo maior atenção dos comerciantes e autoridades de vigilância com relação às condições higiênico-sanitárias durante a comercialização.
\end{abstract}

Palavras-chave: Listeria monocytogenes. Sorvetes. Contaminação microbiológica. 


\section{INTRODUÇÃO}

A ingestão de alimentos contaminados é um dos grandes problemas de saúde pública em nível global. Essas doenças alimentares têm ligação direta com as questões de manipulação, composição do alimento e meio ambiente onde são produzidos e comercializados estes produtos.

Destacam-se como causas dos surtos de doenças de origem alimentar, a forma de produzir e comercializar os produtos, mudanças nas características demográficas, os hábitos culturais, a vigilância de alimentos insuficiente por parte dos governos e a adaptação e emergência de micro-organismos (FORSYTHE, 2002).

A associação de sorvete com quadros de intoxicação ou infeç̧ão alimentar é pouco frequente, mas diversos casos são registrados em todo o mundo envolvendo este alimento, sobretudo aqueles produzidos em condições artesanais, devido principalmente a falhas no tratamento térmico do leite durante o processo (NÓBREGA, 1991).

O sorvete é um produto alimentício a base de leite e é obtido através do congelamento de uma mistura pasteurizada de vários ingredientes, que se constituem em um bom meio de cultura para multiplicação de micro-organismos quando se observa sua constituição nutricional. As condições de comercialização podem contribuir para a contaminação microbiana. Entre estas condições adversas pode-se citar a manipulação excessiva realizada por diferentes pessoas nos buffes self service, e a manutenção do produto em temperaturas próximas ou acima de zero, já que em temperaturas ótimas de conservação a $-12^{\circ} \mathrm{C}$, os sorvetes apresentam-se muito sólidos, dificultando a tomada das porções no caso de serviços de buffe e também a ingestão dos sorvetes.

Dentre os principais perigos microbiológicos encontrados no sorvete, advindos da manipulação, estão Staphyloccoccus aureus, Listeria monocytogenes, Yersinia enterocolitica, Bacillus cereus e Steptococus spp. Todos esses microorganismos patogênicos podem sobreviver em baixas temperaturas. Listeria monocytogenes se destaca entre estes micro-organismos porque pode causar uma série de doenças como septicemia, encefalite e aborto, atingindo, sobretudo grupos de risco, como crianças, grávidas, idosos e indivíduos imunocomprometidos (MIKILITA; CÂNDIDO, 2004; JAY, 2005; GUERRA; BERNARDO, 2006).

Os insumos utilizados na fabricação do sorvete podem apresentar um número elevado de bactérias que poderão sobreviver à fase de pasteurização, quando esta não é adequada. O acréscimo de frutas, nozes, chocolate, corantes e aromatizantes, entre outros, é um importante fator para a contaminação do produto. Caso ocorra algum problema nessa fase, e a desinfecção (pasteurização) não ocorra, bactérias podem sobreviver e se proliferar, causando um sério risco à saúde, mesmo sendo um alimento mantido sob condições de refrigeração ou congelamento, pois não há inibição total dos microrganismos remanescentes (HOFFMANN et al., 2000; BORSZCZ, 2002; DIOGO et al., 2002). 
A forma como são comercializados os sorvetes em buffes self service e em máquinas de sorvete expresso localizadas em locais com pouca condição higiênica pode representar riscos à integridade microbiológica deste produto, e por consequência riscos a saúde do consumidor. Desta forma a pesquisa da incidência de Listeria monocytogenes neste tipo de produto é oportuna devido à escassez destes dados necessários a tomada de ações.

\section{MATERIAL E MÉTODOS}

Foram analisadas 32 amostras de sorvetes comercializados no município de Joaçaba, SC. As amostras foram coletadas aleatoriamente em sete sorveterias da área central da cidade, sendo 16 amostras de sorvete tipo "Expresso" e 16 amostras coletadas em buffet. As coletas foram realizadas nos meses de janeiro e fevereiro de 2009, e as amostras foram acondicionadas em copos plásticos com tampa, usualmente utilizados para a embalagem deste tipo de produto. Após a coleta as amostras foram mantidas congeladas até o momento da análise.

Empregou-se a metodologia de análise ISO 11290-1:2004 (Figura 1). As unidades analíticas de $25 \mathrm{~g}$ foram pré-enriquecidas em $100 \mathrm{~mL}$ de Caldo Universidade de Vermont (UVM - Acumedia cód. 7409$)$, a $30^{\circ} \mathrm{C}\left(+/-1^{\circ} \mathrm{C}\right)$ por 24 horas. A partir das culturas préenriquecidas transferiu-se alíquotas de $0,1 \mathrm{~mL}$ para $10 \mathrm{~mL}$ de caldo de enriquecimento seletivo e diferencial FRASER (Acumedia, cód. 7626) que foi incubado a $35^{\circ} \mathrm{C}\left(+/-1^{\circ} \mathrm{C}\right.$ ) por 24/48 horas em ausência de luz. Após o segundo enriquecimento as culturas de amostras que apresentaram escurecimento do caldo de cultivo (esculinase positiva) foram transferidas para Agar Listeria OTTAVIANI \& AGOSTI (ALOA - Laborclin, cód. 911049) e incubadas a $35-37^{\circ} \mathrm{C}$ por $24 / 48$ horas. Terminado o período de incubação observaram-se o desenvolvimento e as características das colônias. Aquelas que apresentavam coloração azul clara com halo opaco foram consideradas típicas de Listeria monocytogenes e as colônias azuis claras sem halo, típicas de outras espécies de Listeria. As culturas que apresentaram outras características foram consideradas negativas para Listeria sp. Foram selecionadas três colônias características de cada placa e transferidas para Ágar Nutriente (Accumedia 7145) para identificação bioquímica através do kit API Listeria (Biomerieux) e o CAMP Test em Agar Columbia suplementado com sangue de carneiro (CNA - Laborclin, cód. 900525).

\section{RESULTADOS E DISCUSSÃO}

Dentre os sete estabelecimentos avaliados foi detectada a presença de Listeria em seis, e a sorveteria onde não foi verificada a presença de Listeria comercializava sorvetes do tipo expresso. Os resultados de análises das 32 amostras demonstraram que 25,44\% delas apresentaram contaminação por Listeria, sendo 9,8\% L. monocytogenes, 6,25\% L. ivanovii, 3,13\% L. welshimeri. L. innocua foi detectada simultaneamente com L. grayi em uma amostra (3,13\%), e L. grayi ocorreu sozinha em uma amostra (3,13\%). Os dados levantados são apresentados na Tabela 1. 
A literatura registra a ocorrência de Listeria em até $100 \%$ das amostras analisadas em alguns trabalhos. Na Índia, Madhusudan e Thomas (2000) avaliaram a qualidade microbiológica de 30 amostras de sorvetes comercializados em copos e a granel, verificando a presença de $L$. monocytogenes em $53 \%$ no primeiro tipo de sorvete e em $100 \%$ das amostras no segundo. Ao avaliar a multiplicação de L. monocytogenes, neste produto, sob condições de abuso de temperatura por um período de estocagem de 10 dias, estes autores observaram o incremento de mais de 1 ciclo logarítmico à temperatura de $8-10^{\circ} \mathrm{C}$ e de 1 log quando a temperatura oscilava ente 2 a $4^{\circ} \mathrm{C}$, na contagem deste microrganismo.

Windrantz e Arias (2000) registram a ocorrência de 12,3\% $(n=35)$ de presença de Listeria em sorvetes caseiros comercializados em San José, na Costa Rica, isolando dezesseis cepas, sendo oito de L. monocytogenes e oito de L. innoccua. Abrahão (2005) avaliou 60 amostras de sorvetes coletadas em 16 cidades do Estado do Paraná, Brasil e não registraram a ocorrência de Listeria nestas amostras.

Figura 1 - Fluxograma da Análise de Listeria monocytogenes segundo a ISO 11.290:2004.

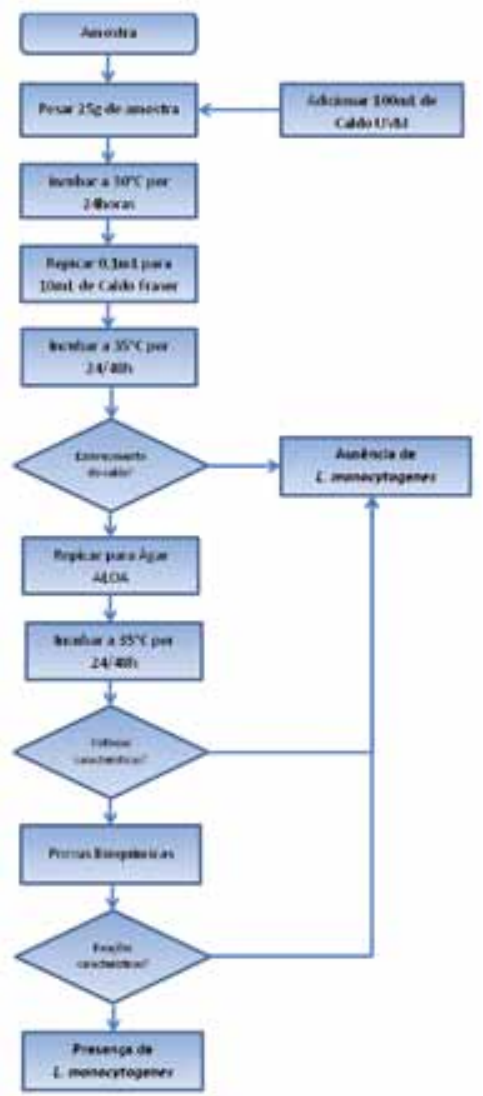


A incidência de Listeria foi maior em sorvetes servidos em buffet $(31,25 \%)$ quando comparado ao sorvete tipo expresso (18,75\%). Pode-se especular que isto se deve à manipulação maior que o sorvete de buffet é submetido, seja pelo fato de ser self service, pelo uso da mesma concha para servir ou a exposição a qual o produto é submetido (as embalagens permanecem abertas dentro dos freezers). Martins et al. (2005) registram a ocorrência de microrganismos patogênicos e deteriorantes (Salmonella sp, Coliformes fecais, Pseudomonas sp, bolores e leveduras) em até $90 \%$ das amostras de utensílios utilizados para servir sorvetes em buffet e Diogo et al. (2002) também observaram esta mesma condição.

Tabela 1 - Resultados de análise de pesquisa de Listeria em sorvetes comercializados na área central do município de Joaçaba, SC, coletados nos meses de janeiro e fevereiro de 2009.

\begin{tabular}{|c|c|c|c|c|}
\hline Amostra & Estabelecimento & $\begin{array}{l}\text { Tipode } \\
\text { Sorvete }\end{array}$ & Sabor & Resultado \\
\hline 1 & $A$ & buffet & creme & Ausente \\
\hline 2 & A & buffet & flocos de chocolate & Ausente \\
\hline 3 & $A$ & buffet & kiwi & Ausente \\
\hline 4 & A & buffet & creme & Ausente \\
\hline 5 & $A$ & expresso & chocolate & Ausente \\
\hline 6 & $A$ & expresso & creme & Ausente \\
\hline 7 & $A$ & expresso & leite condensado & Ausente \\
\hline 8 & A & expresso & kiwi & L. grayi e L. innocua \\
\hline 9 & B & expresso & leite condensado & Ausente \\
\hline 10 & B & expresso & chocolate & L. ivanovii \\
\hline 11 & B & expresso & creme e coco & Ausente \\
\hline 12 & B & expresso & creme com chocolate & Ausente \\
\hline 13 & C & expresso & banana & Ausente \\
\hline 14 & C & expresso & creme & Ausente \\
\hline 15 & C & expresso & abacaxi & Ausente \\
\hline 16 & C & expresso & kiwi com creme & Ausente \\
\hline 17 & D & buffet & milho & L. ivanovii \\
\hline 18 & D & buffet & chiclete & Ausente \\
\hline 19 & D & buffet & abacate & Ausente \\
\hline 20 & D & buffet & passas & Ausente \\
\hline 21 & E & buffet & $\begin{array}{l}\text { chandelly com pedaços } \\
\text { de chocolate }\end{array}$ & L. monocytogenes \\
\hline 22 & $E$ & buffet & chocolate & L. monocytogenes \\
\hline 23 & $E$ & buffet & chocolate & Ausente \\
\hline 24 & $E$ & buffet & $\begin{array}{l}\text { cereja com pedaços da } \\
\text { fruta }\end{array}$ & L. monocytogenes \\
\hline 25 & $\mathrm{~F}$ & buffet & romeu e julieta & Ausente \\
\hline
\end{tabular}




\begin{tabular}{l|l|l|l|l}
\hline 26 & F & buffet & flocos de chocolate & L. welshimeri \\
\hline 27 & F & buffet & uva & Ausente \\
\hline 28 & F & buffet & amendoim & Ausente \\
\hline 29 & G & expresso & leite condensado & Ausente \\
\hline 30 & G & expresso & chocolate & L.grayi \\
\hline 31 & G & expresso & leite condensado & Ausente \\
32 & G & expresso & chocolate & Ausente \\
\hline
\end{tabular}

O sabor de sorvete onde foi detectada a maior ocorrência de Listeria, inclusive $L$. monocytogenes, foi o de chocolate. Pode-se inferir que se deve ao maior consumo desse sabor, portanto mais manipulado pelos consumidores, entretanto o número de amostras coletadas deste sabor foi consideravelmente maior do que dos demais.

\section{CONCLUSÃO}

Os dados demonstraram uma presença considerável $(9,8 \%)$ de Listeria monocytogenes, sendo a ocorrência observada apenas nos sorvetes servidos em buffet, o que aponta para a necessidade de maior atenção dos comerciantes e autoridades de vigilância com relação às condições higiênico-sanitárias durante a comercialização. Embora existam indícios não se pode concluir que os índices de contaminação devam-se unicamente à exposição ou manipulação, pois não foi o foco do trabalho.

As condições de conservação e consumo, deste alimento, em princípio não permitem a multiplicação acentuada de $L$. monocytogenes, entretanto a frequência de ocorrência em um dos estabelecimentos é bastante preocupante, já que o consumidor não associa o alimento com risco de contrair uma doença de origem alimentar, e se a condição de manipulação for a responsável pela contaminação existente, outros patógenos importantes poderiam ser encontrados.

A ocorrência de L. monocytogenes apenas nas amostras coletadas em buffe sugere que se devem implantar medidas rigorosas de higiene nestes estabelecimentos, como evitar que o consumidor manipule o produto e que se coloquem barreiras físicas que protejam o alimento.

A diversidade de espécies encontradas foi grande, embora a coexistência entre elas não tenha sido observada com frequência.

Este trabalho demonstrou que o sorvete pode ser um potencial veículo de transmissão da listeriose. Sugere-se que em um trabalho futuro sejam realizadas contagens deste microrganismo para se ter uma ideia mais abrangente do risco que a população consumidora está exposta. 


\title{
SURVEY OF Listeria monocytogenes IN SOFT ICE CREAM AND SELF SERVICE ICE CREAM SOLD IN JOAÇABA, SC - BRAZIL.
}

\begin{abstract}
Listeria monocytogenes is the pathogen that causes listeriosis, and found in newborns, pregnant women, elderly and immuno-depressed their risk group. This bacterium can be present in food, even in a state of cooling, which can survive and multiply. The ice cream is a food obtained through a mixture of milk and other ingredients, which may suffer from microbiological contamination. Given this possibility, this study was conducted to investigate the contamination by Listeria monocytogenes in ice cream sold in seven stores in the city of Joaçaba, SC. 32 samples were collected of ice cream, 16 served buffet style and 16 of soft ice cream type during the months of January and February 2009. Was observed a rate of contamination by bacteria of the genus Listeria of $25,44 \%$ and $9.8 \%$ of $L$. monocytogenes, $6.25 \%$ of $L$. ivanovii, $3.13 \%$ of $L$. welshimeri. $L$. innocua was detected simultaneously with L. grayi on one sample (3.13\%), and L. grayi was isolated in another sample (3.13\%). The data showed a high presence of the genus Listeria, especially in ice cream served in a buffet, suggesting more attention from traders and health inspection authorities related to sanitary conditions during trading.
\end{abstract}

Keywords: Listeria monocytogenes. Ice cream. Microbiological contamination.

\section{REFERÊNCIAS}

ABRAHÃO, P. R. S. Ocorrência de Listeria monocytogenes e de outros microorganismos em gelados comestíveis fabricados e comercializados na região metropolitana de Curitiba, Paraná. 2005. Dissertação (Mestrado em Microbiologia, Parasitologia e Patologia). Departamento de Patologia Básica - Setor de Ciências Biológicas da Universidade Federal do Paraná, 2005.

BORSZCZ, V. Implantação do Sistema APPCC para Sorvetes: Aplicação na Empresa Kimyto. 2002. Dissertação (Mestrado em Engenharia de Alimentos) - Universidade Federal de Santa Catarina, Florianópolis, 2002.

DIOGO, G. et al. Avaliação microbiológica de sorvetes comercializados na cidade de Ponta Grossa - PR e da água usada na limpeza das colheres utilizadas para servi-los. Biological and Health Sciences, 8(1): 23-32, 2002.

FORSYTHE, S. J. Microbiologia da segurança alimentar: 1 ed. Porto Alegre: Artmed, 2002. 169 p. 
GUERRA, M. M.; BERNARDO, F. A. Multiplicação e sobrevivência de Listeria monocytogenes sob condições ecológicas desfavoráveis. Higiene Alimentar, São Paulo, v. 20, n.139, p.65-71, mar. 2006.

HOFFMAN, F. et al. Qualidade higiênico-sanitária de sorvetes comercializados na cidade de São José do Rio Preto (SP) Brasil. Higiene Alimentar, São Paulo, v.11, n.76, p.62-68, nov. 2000.

ISO. INTERNATIONAL STANDART ORGANIZATION. ISO 11290-2:1998/Amd.1:2004 Microbiology of food and animal feeding stuffs - Horizontal method for the detection and enumeration of Listeria monocytogenes - Part 1: Detection method. Amendment 1: Modification of enumeration medium. Geneve: International Standart Organization. 15/10/2004. 20p.

JAY, J. M, Microbiologia de alimentos. 6 ed. São Paulo: editora Artmed, 2005. 316 p.

MADHUSUDAN, K.; THOMAS, P. Incidence of pathogenic psychrotrophs in ice creams sold in some retail outlets in Munbai, India. Food Control, v. 11. n. 2. p. 77-83, 2000.

MARTINS, O. M.; et al. Qualidade microbiológica da água de lavagem das conchas de aço inoxidável de sorveterias da cidade do Recife, PE. Higiene Alimentar, São Paulo, v.19. n.136. p. 96-100, out. 2005.

MIKILITA, I. S.; CÂNDIDO, L. M. B. Fabricação de sorvete: perigos significativos e pontos críticos de controle. Brasil Alimentos, São Paulo, n.26, p.34-37, jul./ago. 2004.

NÓBREGA , I.C.C. Condições microbiológicas e higiênico - sanitárias de sorvetes produzidos em pequenas fábricas de João Pessoa, PB. Higiene Alimentar, São Paulo, v. 5. n. 18, p. 28-32, jun., 1991.

WINDRANTZ, P.; ARIAS, M.L. Evaluation on bacteriological quality of ice cream sold at San Jose, Costa Rica. Arch. Latinoamer. Nutric., Caracas, v.50, n.3, p.301-303, 2000. 


\section{SOBRE OS AUTORES}
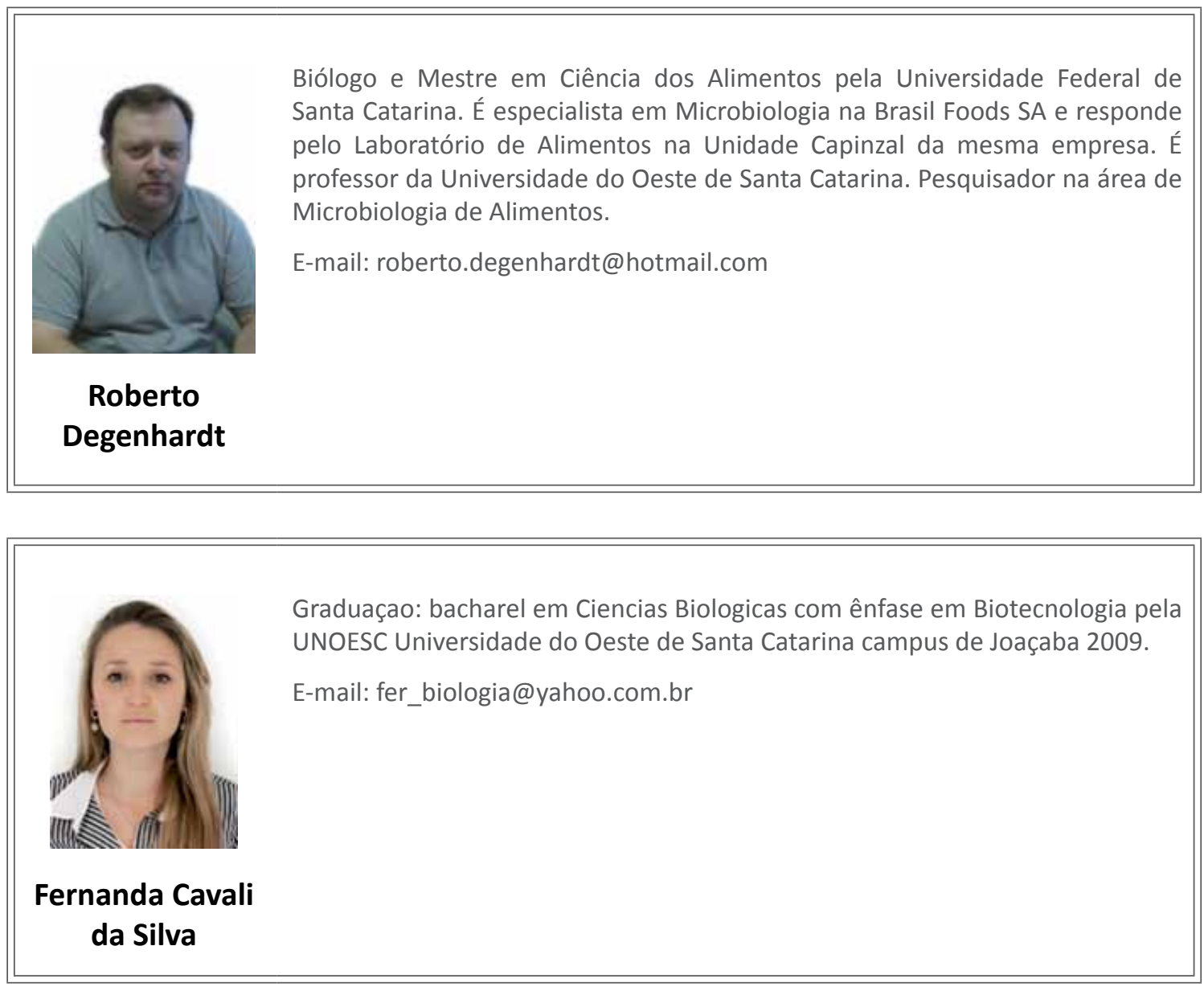